\title{
Up-regulation of the BTG2 gene in TPA- or RA-treated HL-60 cell lines
}

\author{
BYOUNG-OK CHO ${ }^{1}$, YONG-WOOK JEONG ${ }^{2}$, SEOUNG-HOON KIM ${ }^{3}$, \\ KUN PARK $^{4}$, JI-HYE LEE ${ }^{5}$, GI RYANG KWEON ${ }^{6}$ and JONG-CHUN PARK ${ }^{2}$
}

\begin{abstract}
${ }^{1}$ Department of Pharmacology, College of Medicine, Chosun University, 375 Seosuk-Dong, Dong-ku, Gwangju 501-759; Departments of ${ }^{2}$ Microbiology and ${ }^{3}$ Pharmacology, College of Medicine, Seonam University, Kwangchi-Dong 720, Namwon, Chunpook 590-711; Departments of ${ }^{4}$ Dermatology and ${ }^{5}$ Internal Medicine and College of Medicine Eulji University, Hagye 1-dong, Nowon-gu, Seoul 139-711; ${ }^{6}$ Department of Biochemistry, School of Medicine, Chungnam National University, Joong-ku, Taejon 301-721, Korea
\end{abstract}

Received August 9, 2007; Accepted October 8, 2007

\begin{abstract}
The key pathogenesis of leukemia is the defection of the differentiation processes of hematopoietic stem cells. There are five APRO (anti-proliferative) genes, BTG1, BTG2, BTG3, TOB and TOB2, and it was reported that certain APRO genes are associated with cell differentiation. However, it is still unknown whether APRO genes are related with the differentiation process of blood cells. In this study, we investigated the expression of APRO genes in 12-O-tetradecanoylphorbol-13-acetate (TPA) or retinoic acid (RA)treated HL-60 cell lines. Our data show that the expression of the BTG2 gene was increased in $32 \mathrm{nM}$ TPA-treated and $1 \mu \mathrm{M}$ RA-treated HL-60 cells, but the expression of the BTG1 and BTG3 genes was not increased. The expression of BTG2 in TPA- or RA-treated HL-60 cells was also increased even in the presence of cyclohexamide, which is an inhibitor of translation, implying that the increased expression of BTG 2 mRNA did not require the new synthesis of another protein. Notably, the up-regulation of BTG2 in TPA- or RA-treated HL-60 cells was observed prior to the increased expression of $\mathrm{p} 21$. Our data show that PKC pathways are uninvolved with the upregulation of BTG2 in TPA- or RA-treated HL-60 cells. Thus, the up-regulation of BTG2 genes may be involved in the differentiation process of HL-60 cells after TPA or RA treatment. Furthermore, this event occurred prior to p21 expression, implying that the BTG2 expression plays a role at a very early point during the differentiation processes of hematopoietic cells.
\end{abstract}

Correspondence to: Dr Jong-Chun Park, Department of Microbiology, College of Medicine, Seonam University, Kwangchi-Dong 720, Namwon, Chunpook 590-711, Korea

E-mail:pjcoli@hanmail.net

Key words: BTG2, 12-O-tetradecanoylphorbol-13-acetate, retinoic acid, hematopoietic differentiation

\section{Introduction}

The human leukemia HL-60 cell line was derived from a female patient diagnosed with acute promyelocytic leukemia. The HL-60 cells are differentiated into monocyte/macrophagelike lineages by 12 - $O$-tetradecanoylphorbol-13-acetate (TPA) or granulocyte-like lineages by RA treatment $(1,2)$. The TPAor RA-induced differentiation of HL-60 cells is characterized by cell cycle arrest through the up-regulation of a cell cycle inhibitor, such as p21 or p27 $(3,4)$. These processes are regulated by the protein kinase $\mathrm{C}$ (PKC), a family of serine/ threonine-specific kinases, which is involved in cell differentiation and growth. The activated PKC up-regulates p21 and $\mathrm{p} 27$, resulting in inhibiting the phosphorylation of $\mathrm{pRb}$ and enhancing cell cycle arrest in G1 $(5,6)$. However, the precise molecular mechanisms underlying TPA- or RA-induced differentiation of the HL-60 cells are largely unknown.

The name of APRO is derived from the consensus function of the gene family as anti-proliferative (7). The human APRO genes are BTG1, BTG2/TIS21 (named PC3 in the rat), BTG3, TOB and TOB2. In the cell differentiation process, the expression and molecular mechanisms of antiproliferative (APRO) genes are still largely unknown. BTG1 and BTG2 genes are expressed early during the G0/G1 transition phase of the cell cycle $(8,9)$. BTG1 is essentially expressed in arrested and in differentiated cells, whereas it is down-regulated as the cells enter the growth cycle. Thus, accumulating data suggest that the BTG/TOB family members may be involved in the differentiation processes by inhibition of the proliferation process.

In this study, to confirm the roles of APRO genes in hematopoietic cell differentiation, we investigated the expression of APRO genes in TPA- or RA-treated HL-60 cells by RT-PCR analysis.

\section{Materials and methods}

Cells and cell culture. The HL-60 cells were grown at $37^{\circ} \mathrm{C}$ in a humidified atmosphere of $95 \%$ air and $5 \% \mathrm{CO}_{2}$. The culture medium was RPMI-1640 supplemented with $10 \%$ 
(A)

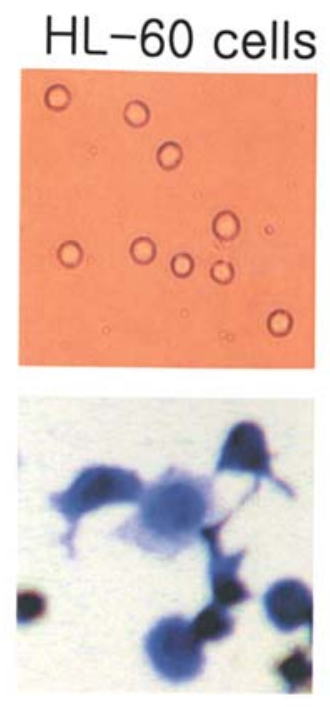

(C)

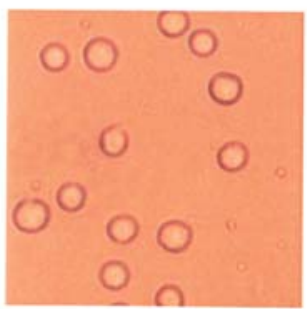

RA

Figure 1. Morphological changes of HL-60 cells after TPA or RA treatment. Cells were incubated without (A) or with $32 \mathrm{nM}$ TPA (B) and $1 \mu \mathrm{M}$ RA (C) for $24 \mathrm{~h}$. Photographs were taken after crystal violet staining (x200).

heat-inactivated fetal bovine serum (HyClone, Logan, UT, USA), penicillin $(100 \mathrm{U} / \mathrm{ml})$ and streptomycin $(100 \mu \mathrm{g} / \mathrm{ml})$ (Gibco BRL Laboratories, Grand Island, NY, USA).

The induction of cell differentiation. The HL-60 cells $\left(2 \times 10^{5} / \mathrm{ml}\right)$ were seeded into $60-\mathrm{mm}$ dishes and cultured at $37^{\circ} \mathrm{C}$ for $24 \mathrm{~h}$. For the induction of differentiation, cells were treated with $32 \mathrm{nM}$ TPA (Sigma Co., USA) and $1 \mu \mathrm{M}$ RA (Sigma Co.), respectively.

Crystal violet staining. To investigate the morphological change, cells were cultured for 1 day after TPA or RA treatment. TPA-treated cells were rinsed gently twice with Dulbecco's phosphate-buffered saline (Gibco BRL Laboratories) and stained with $1 \%$ crystal violet at $37^{\circ} \mathrm{C}$ for $5 \mathrm{~min}$. Crystal violet was gently washed with sterile deionized water and the crystal violet-stained cells were examined by an inverted phase-contrast light microscope. RA-treated cells were examined using a hemacytometer.

Cell proliferation assay. TPA- or RA-treated HL-60 cells $\left(1.5 \times 10^{5} / \mathrm{ml}\right)$ were counted microscopically using a hemocytometer at various time points. TPA-treated cells were counted for 1, 2, 3 and 4 days and RA-treated cells were counted for 7 days. All experiments were performed in triplicate.

Reverse transcription-polymerase chain reaction (RT-PCR). Total RNA was isolated from cells using the Tri Reagent
(A)

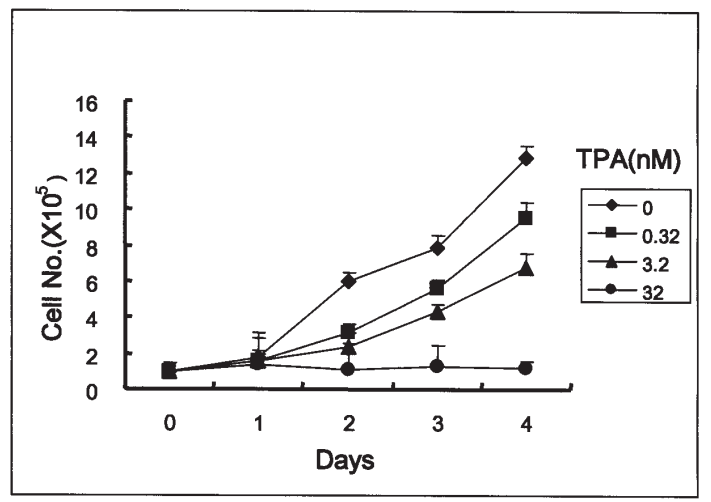

(B)

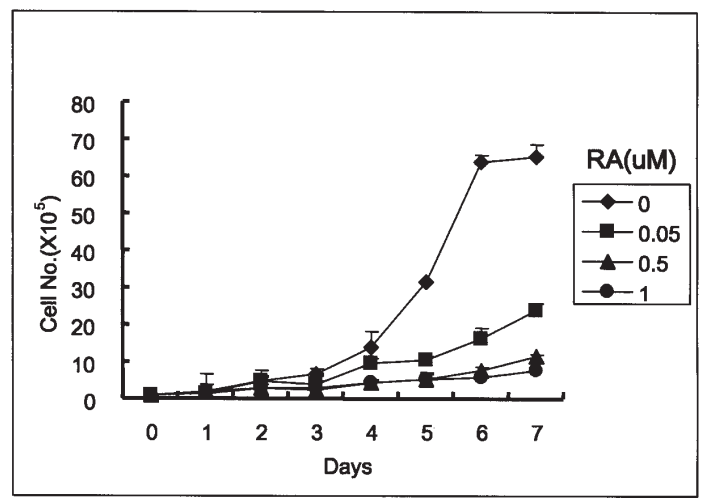

Figure 2. Decreased cell proliferation rates in TPA- or RA-treated HL-60 cells. Cells were exposed with 0-32 nM TPA for 4 days (A) and with 0-1 $\mu \mathrm{M}$ RA for 7 days (B)

(Molecular Research Center Co., USA) according to the manufacturer's instructions and quantitated by a spectrophotometer. Total RNA (1 $\mu \mathrm{g})$ was reverse-transcribed using an M-MLV reverse transcriptase (Promega Co., USA). The PCR reaction was carried out according to the manufacturer's instructions (Perkin-Elmer Co., USA). Each of the cDNAs was amplified with primers: for GAPDH (sense 5'-CGTCT TCACCACCAT GGAGA-3'; antisense 5'-CGGCCATCAC GCCACAGTTT-3'), BTG1 (sense 5'-CGTGTCCTTC ATCTCCAAGT-3'; antisense 5'-CTGATTCGGCTGTCT ACCAT-3'), BTG2 (sense 5'-GGCACTCACAGAGCA CTACA-3'; antisense 5'-CTGCCATCACGTAGTTCTTG-3') and BTG3 (sense 5'-CAGGCCTACAGATGTATTCG-3'; antisense 5'-TGGAACAGGAGGAGGATAGT-3'), producing PCR products of GAPDH, 300 bp, BTG1, 399 bp, BTG2, $334 \mathrm{bp}$ and BTG3, $599 \mathrm{bp}$. Briefly, $20 \mu 1$ of reaction mixture including $2 \mu \mathrm{l}$ of $10 \mathrm{X}$ buffer [100 mM Tris- $\mathrm{HCl}(\mathrm{pH} 8.3)$, $500 \mathrm{mM} \mathrm{KCl}, 15 \mathrm{mM} \mathrm{MgCl}$ ], $200 \mu \mathrm{M}$ dNTPs, each $25 \mathrm{pM}$ of primer, 0.5 units of Taq polymerase (Takara Co., Japan) and $1 \mu 1$ of cDNA was performed as follows: initial denaturation for $5 \mathrm{~min}$ at $94^{\circ} \mathrm{C}$, followed by 30-35 cycles of denaturation for $30 \mathrm{sec}$ at $94^{\circ} \mathrm{C}$, annealing for $30 \mathrm{sec}$ at $57^{\circ} \mathrm{C}$ (BTG3 primer was $58^{\circ} \mathrm{C}$ ), extension for $30 \mathrm{sec}$ at $72^{\circ} \mathrm{C}$, final extension for $7 \mathrm{~min}$ at $72^{\circ} \mathrm{C}$. The PCR products $(10 \mu \mathrm{l})$ were separated by electrophoresis in $1.5 \%$ agarose gel with ethidium bromide. Band density was analyzed by a densitometer. 
(A)
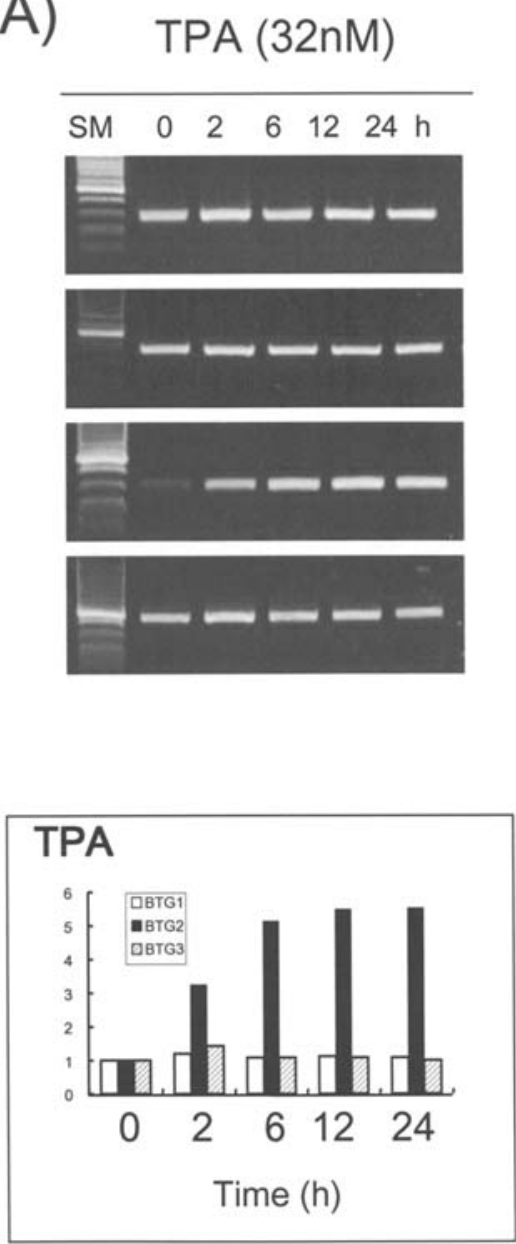

(B)
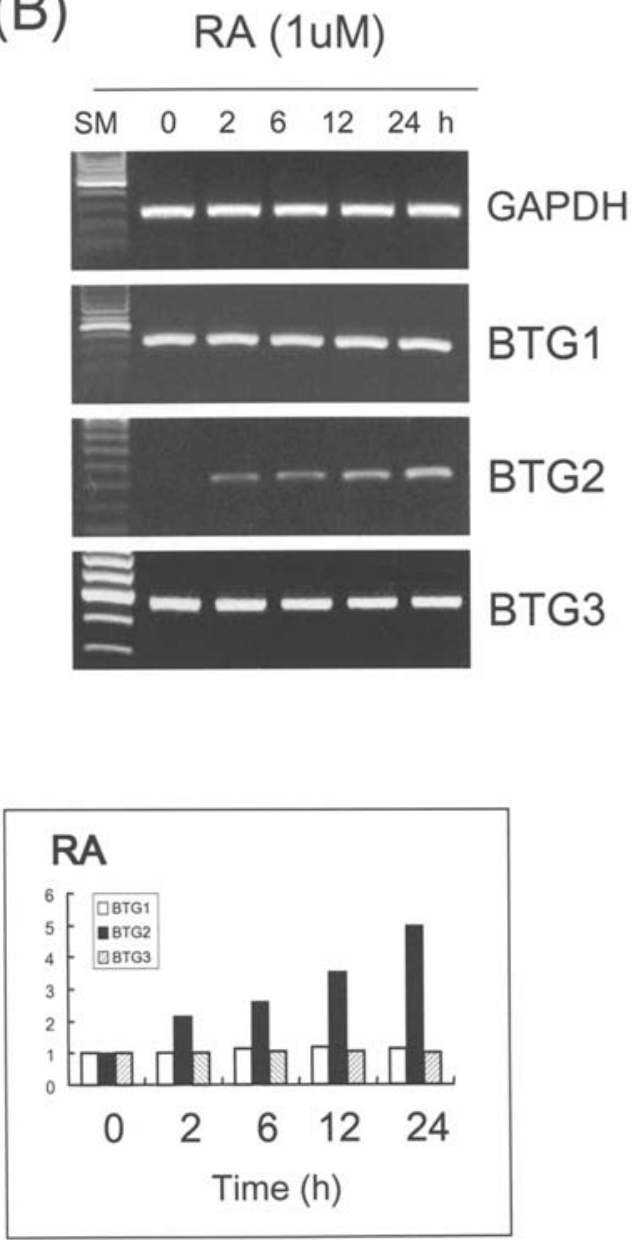

Figure 3. Expression of BTG1, BTG2 and BTG3 in TPA- or RA-treated HL-60 cells. Cells were incubated with 32 nM TPA or $1 \mu$ M RA for 24 h. After the incubation, total RNA was isolated for RT-PCR analysis which was conducted using gene-specific primers for the target gene. The level of the BTG1, BTG2 and BTG3 expression was quantified by a densitometer to measure the relative values; SM, size marker.
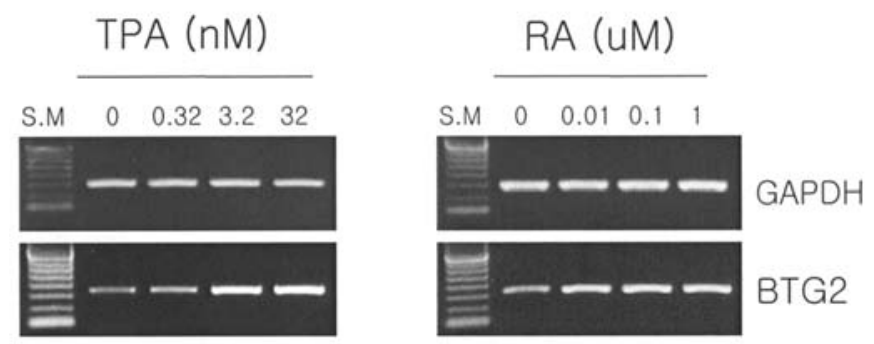

Figure 4. The up-regulation of BTG2 in TPA- or RA-treated HL-60 cells. Cells were treated with various concentrations of TPA $(0-2 \mathrm{nM})$ or RA (0-1 $\mu \mathrm{M})$. Total RNA was isolated for RT-PCR analysis which was conducted using gene-specific primers for the target gene.

\section{Results}

Morphological changes of TPA- or RA-treated HL-60 cells. Morphological changes of TPA- or RA-treated leukemia cells were examined by an inverted phase-contrast light microscope (Fig. 1). The HL-60 cells, growing floating cells when not treated, adhered to the surface of a cell culture dish with a monocyte/marcrophage-like lineage differentiation by TPA treatment (Fig. 1B), whereas some became swollen with granulocyte-like lineage differentiation by RA treatment (Fig. 1C).

Decreased cell proliferation rates in TPA- or RA-treated $H L-60$ cells. The numbers of viable HL-60 cells were counted for 4 days after TPA or RA treatment at a range of doses (Fig. 2). The number of viable cells was markedly decreased in a dose-dependent manner in both TPA- (Fig. 2A) and RAtreated HL-60 cells (Fig. 2B).

Up-regulation of the BTG2 $m R N A$ expression in TPA- or RAtreated HL-60 cells. To study the expression of BTG1, BTG2 and BTG3 genes, HL-60 cells were treated with TPA or RA for $24 \mathrm{~h}$. The expression of BTG2 gene was markedly increased by $6 \mathrm{~h}$ after TPA treatment and $12 \mathrm{~h}$ after RA treatment, but the expression of BTG1 and BTG3 genes was not increased in TPA- or RA-treated HL-60 cells (Fig. 3). In addition, cells were treated with different concentrations from 0.32 to $32 \mathrm{nM}$ TPA or 0.01 to $1 \mu \mathrm{M}$ RA for $24 \mathrm{~h}$. The increased expression of BTG2 was clearly observed at 3.2 nM TPA and $0.01 \mu \mathrm{M}$ RA in HL-60 cells (Fig. 4).

In order to investigate whether the up-regulation of BTG2 needed a new protein synthesis such as transcription factors, 

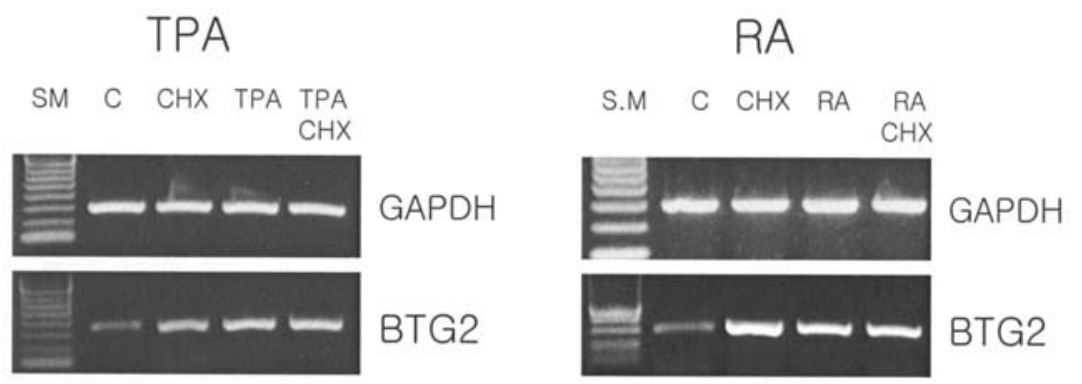

Figure 5. No effect of cycloheximide on the expression of BTG2. Cells were pretreated for 30 min with cycloheximide prior to TPA or RA treatment. An increased expression of BTG2 was clearly observed in the presence of CHX; C, control; CHX, cycloheximide.

(A)

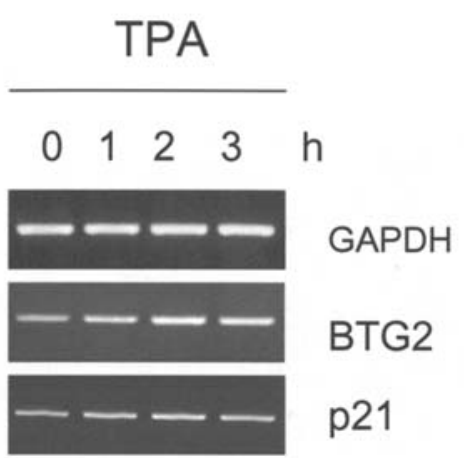

(B)

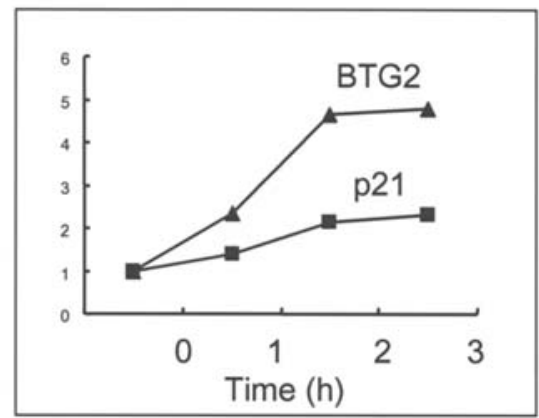

Figure 6. The up-regulation of BTG2 prior to the expression of p21 mRNA in TPA-treated HL-60 cells. The cells were treated with $32 \mathrm{nM}$ TPA for $3 \mathrm{~h}$. Total RNA was isolated for RT-PCR analysis and the expression levels of BTG2 and p21 were analyzed by RT-PCR analysis using specific primers (A) and then quantified by a densitometer (B).

(A)
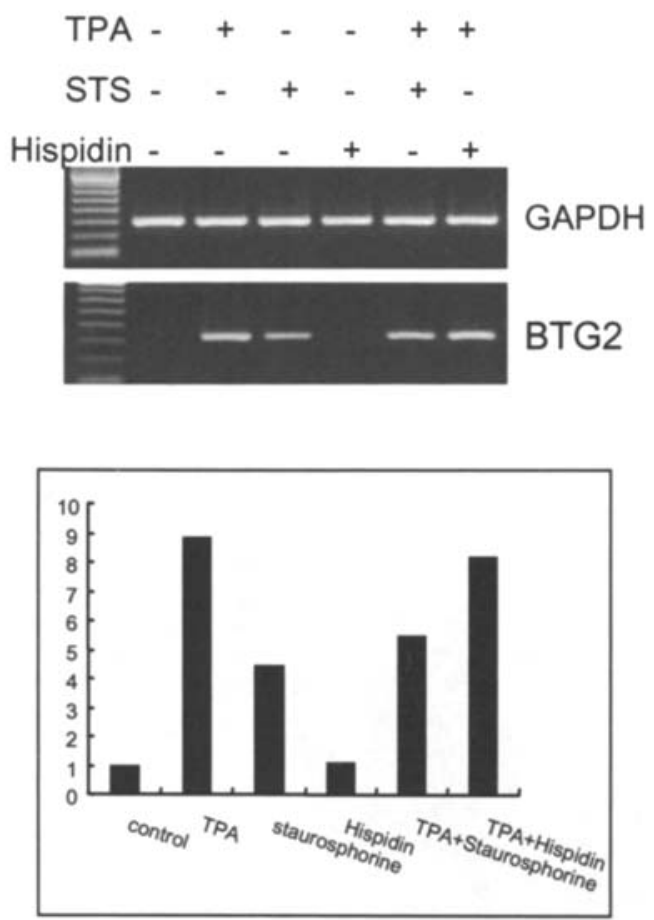
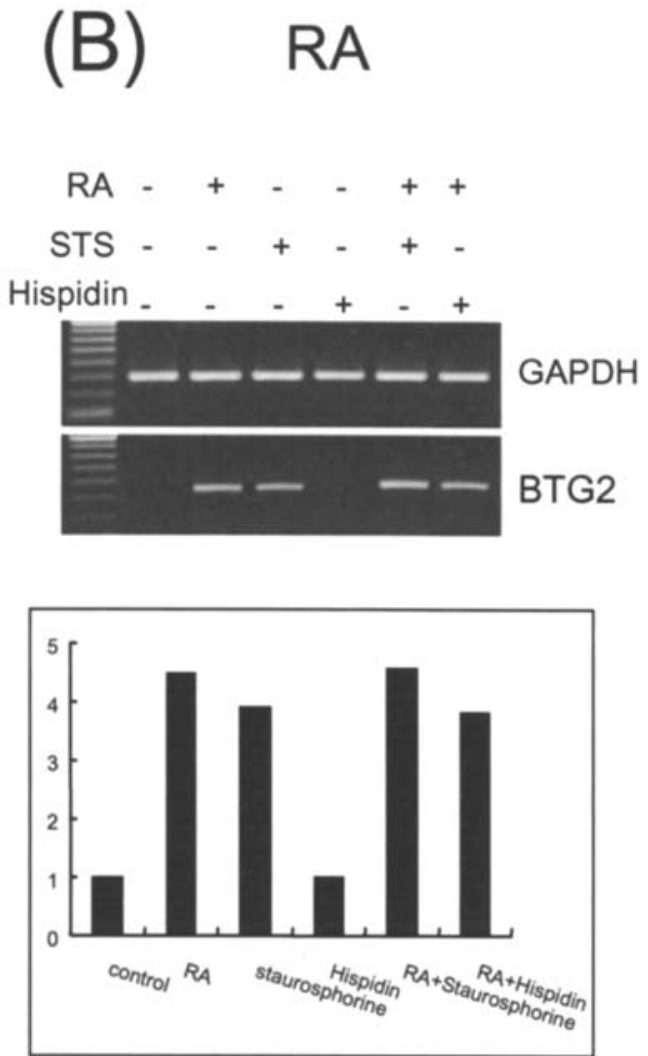

Figure 7. The PKC pathway is not involved in the BTG2 expression in TPA- or RA-treated HL-60 cells. HL-60 cells were pretreated with PKC inhibitors, staurosphorine or hispidin for $1 \mathrm{~h}$ and then cells were incubated with $32 \mathrm{nM}$ TPA (A) or $1 \mu \mathrm{M} \mathrm{RA}$ (B) for $6 \mathrm{~h}$. Total RNA was isolated for RT-PCR analysis and the expression levels of BTG2 were analyzed by RT-PCR analysis using specific primers and then quantified by a densitometer. 
HL-60 cells were pretreated with cycloheximide (CHX), which is an inhibitor of translation and then cells were treated with TPA or RA. Cycloheximide was used at a concentration of $4 \mu \mathrm{g} / \mathrm{ml}$ to inhibit protein synthesis in HL-60 cells. The expression of BTG2 was increased even in the presence of $\mathrm{CHX}$, implying that the up-regulation of the BTG2 expression in TPA- or RA-treated HL-60 cells may not be required in a new protein synthesis (Fig. 5).

The up-regulation of p21 in TPA-treated HL-60 cells is an important event in cell differentiation processes for cell cycle arrest. Notably, the BTG2 expression was more rapidly increased than the p21 expression in TPA-treated HL-60 cells (Fig. 6).

To investigate whether the increased expression of BTG2 is regulated by the PKC pathway, $10 \mathrm{nM}$ staurosphorine (STS) and $10 \mu \mathrm{M}$ hispidin, PKC inhibitors, were pretreated in TPA(Fig. 7A) or RA-treated HL-60 cells (Fig. 7B). The expression of BTG2 was not attenuated by the pretreatment of PKC inhibitors, implying that the PKC pathway is not involved in the expression of BTG2 gene in TPA- or RA-treated HL-60 cells.

\section{Discussion}

Human leukemic HL-60 cells can be terminally differentiated into granulocytes by RA treatment or monocytes/macrophages by TPA treatment (2). The treatment of HL-60 cells with TPA or RA induces the functional and morphological changes that are characteristic of terminally-differentiated monocyte/ macrophages or granulocytes. Regardless of the direction of differentiation, the common initial pathway to differentiation is cell cycle arrest by several mechanisms.

It was recently reported that APRO genes were able to inhibit the proliferation of cells by arresting G1-S progression. Furthermore, it was proved that BTG2 and BTG3 genes were the primary responsive genes super-induced by TPA (7). Notably, the overexpression of BTG2 inhibits G1-S progression through the transcriptional regulation of cyclin D1 in the presence of $\mathrm{pRB}$ and BTG2 down-regulates the expression of cyclin E and cdk4 $(10,11)$. The genetic ablation of BTG2 prevents G2 arrest in ES cells in a p53-dependent manner, supporting that BTG2 induces G2/M arrest (8). These findings strongly support that BTG2 may play a role in the differentiation process in cells through cell cycle arrest.

In this study, our data showed that the expression of BTG2 in HL-60 cells was clearly increased with TPA or RA treatment. Furthermore, it occurred prior to the p21 expression. The cell cycle inhibitor, p21, plays a critical role in the arrest of the G1 cell cycle by interacting with multiple cellular targets. In addition, p21 has been implicated in mediating growth arrest in terminal differentiation (4). Thus, according to our data, the up-regulation of BTG2 is rapidly regulated in the beginning of differentiation and this finding suggests that the BTG2 gene may be an immediately early responsive gene in TPA- or RA-treated HL-60 cells for the induction of differentiation processes.

PKCs comprise a family of serine/threonine kinases, which promote cell survival and repress cell death. Various studies have shown that PKCs play an important role in the regulation of cellular growth in haematopoietic neoplasms
$(12,13)$ and in the anti-apoptotic signaling pathway in neuron and haematopoietic cells (14). However, in this study, the PKC pathway was not involved in the up-regulation of BTG2 after TPA or RA treatment.

In conclusion, the increased expression of BTG2 gene may be an important event in TPA- or RA-treated HL-60 cells for cellular differentiation and these data provide basic information for understanding the blood cell differentiation process. Further studies will be needed to define the precise roles of BTG2, involving granulocytes and monocyte/ macrophage differentiation in cells.

\section{References}

1. Birine GD: The HL-60 cell line: a model system for studying human myeloid cell differentiation. Br J Cancer 9 (Suppl): 41-45, 1988.

2. Collins SJ: The HL-60 promyelocytic leukemia cell line: proliferation, differentiation and cellular oncogene expression. Blood 70: 1233-1244, 1987.

3. Das D, Pintucci G and Stern A: MAPK-dependent expression of p21WAF and p27kip1 in PMA-induced differentiation of HL-60 cells. FEBS Lett 472: 50-52, 2000.

4. Parker SB, Eichele G, Zhang P, Rawls A, Sands AT, Bradley A, Olson EN, Harper JW and Elledge SJ: p53-independent expression of p21Cip 1 in muscle and other terminally differentiating cells. Science 267: 1024-1027, 1995.

5. Vrana JA, Kramer LB, Saundera AM, Zhang XF, Dent P, Povirk LF and Grant S: Inhibition of protein kinase $C$ activatormediated induction of p21cip 1 and p27kip 1 by deoxycytidine analogs in human leukemia cells: relationship to apoptosis and differentiation. Biochem Pharmacol 58: 121-131, 1999.

6. White SL, Belov L, Barber N, Hodgkin PD and Christopherson RI: Immunophenotypic changes induced on human HL-60 leukaemia cells by 1,25- dihydroxyvitamin D3 and 12-O-tetradecanoyl Phorbol-13-acetate. Leuk Res 29: 1141-1151, 2005.

7. Matsuda S, Rouault J, Magaud J and Berthet C: In search of a function for the TIS21/PC3/BTG1/TOB family. FEBS Lett 497: 67-72, 2001.

8. Rouault JP, Falette N, Geuhenneux F, Guillot C, Rimokh R, Wang Q, Berthet C, Moryet-Lalle C, Savatier P, Pain B, Shaw P, Berger R, Samarut J, Magaud JP, Ozturk M, Samarut C and Puisieux A: Identification of BTG2, an antiproliferative p53dependent component of the DNA damage cellular response pathway. Nat Genet 14: 482-486, 1996.

9. Tirone F: The gene PC3(TIS21/BTG2), prototype member of the PC3/BTG/TOB family; regulator in control of cell growth, differentiation, and DNA repair. J Cell Physiol 2: 155-157, 2001.

10. Duriez C, Falette N, Audoynaud C, Moyret-Lalle C, Bensaad K, Courtois S, Wang Q, Soussi T and Puisieux A: The human BTG2/TIS21/PC3 gene: genomic structure, transcriptional regulation and evaluation as a candidate tumor suppressor gene. Genes 282: 207-214, 2002.

11. Guardavaccaro D, Corrente G, Covone F, Micheli L, D'Agnano I, Starace G, Caruso M and Tirone F: Arrest of G(1)-S progression by the p53-inducible gene PC3 is Rb-dependent and relies on the inhibition of cyclin D1 transcription. Mol Cell Biol 20: 1797-1815, 2000.

12. Lim IK, Lee MS, Ryu MS, Park TJ, Fujiki H, Eguchi H and Paik WK: Overexpression of TIS21 in 293 cells induces growth inhibition by down-regulation of the cyclin $E$ and cyclindependent kinase 4 proteins. Mol Carcinog 23: 25-35, 1998.

13. Hofmann $\mathrm{J}$ : Modulation of protein kinase $\mathrm{C}$ in antitumor treatment. Rev Physiol Biochem Pharmacol 142: 1-96, 2000.

14. Liao YF, Hung YC, Chang WH, Tsay GJ, Hour TC, Hung HC and Liu GY: The PKC delta inhibitor, rottlerin, induces apoptosis of haematopoietic cell lines through mitochondrial membrane depolarization and caspases' cascade. Life Sci 77: 707-719, 2005.

15. Brodie C and Blumberg PM: Regulation of cell apoptosis by protein kinase C delta. Apoptosis 8: 19-27, 2003. 